\title{
LLNL DATA COLLECTION DURING NOAA/ETL COPE EXPERIMENT
}

\author{
Test Plan
}

David D. Mantrom

Imaging \& Detection Program

September 6, 1995

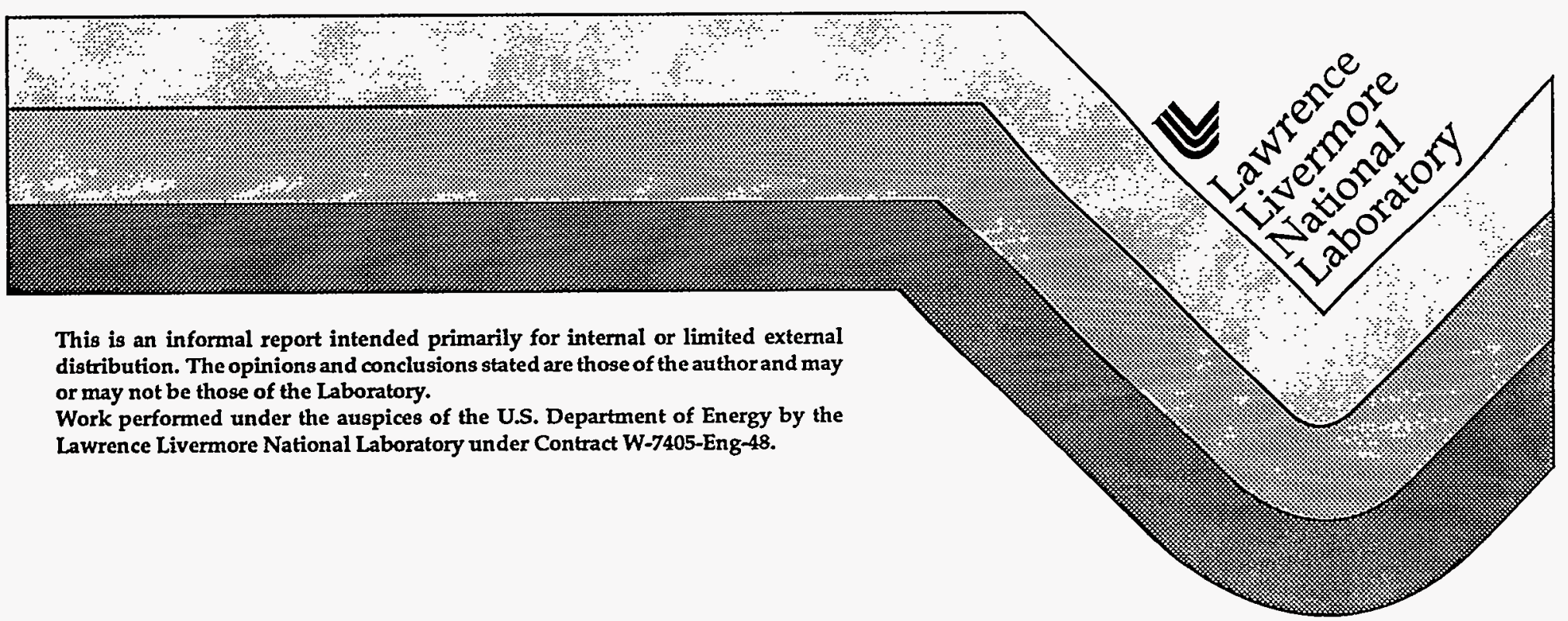

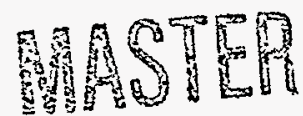




\section{DISCLAIMER}

This document was prepared as an account of work sponsored by an agency of the United States Government. Neither the United States Government nor the University of California nor any of their employees, makes any warranty, express or implied, or assumes any legal liability or responsibility for the accuracy, completeness, or usefulness of any information, apparatus, product, or process disclosed, or represents that its use would not infringe privately owned rights. Reference herein to any specific commercial product, process, or service by trade name, trademark, manufacturer, or otherwise, does not necessarily constitute or imply its endorsement, recommendation, or favoring by the United States Government or the University of California. The views and opinions of authors expressed herein do not necessarily state or reflect those of the United States Government or the University of California, and shall not be used for advertising or product endorsement purposes.

This report has been reproduced directly from the best available copy.

Available to DOE and DOE contractors from the Office of Scientific and Technical Information P.O. Box 62, Oak Ridge, TN 37831

Prices available from (615) 576-8401, FTS 626-8401

Available to the public from the National Technical Information Service

U.S. Department of Commerce 5285 Port Royal Rd., Springfield, VA 22161 


\section{DISCLAIMER}

Portions of this document may be illegible in electronic image products. Images are produced from the best available original document. 


\section{Introduction}

COPE is the acronym for the Coastal Ocean Probe Experiment, to be conducted by NOAA/ETL off the northern Oregon coast in September-October 1995. In general terms, ETL desires to collect data on how various types of microwave sensors including radar would respond to internal wave-induced modulations to the ocean surface, and what effects propagation through the atmosphere might have on the data collected. The test site was chosen because strong surface effects associated with internal gravity waves have been regularly observed there and the presence of a coastal mountain range would allow a large land-based radar to be situated high enough to image these internal wave effects.

In COPE, ETL will field a broad suite of microwave sensors, and a variety of seatruth and atmospheric-truth instruments. These will include a land-based, high power, $X$ - and Ka-band real aperture radar (RAR) located atop a $3000 \mathrm{ft}$ high coastal peak, various water column, surface wave, air-sea interface, and atmospheric sensors on the FLIP measurement platform to be moored approximately 15 miles offshore, various active and passive microwave devices onboard a blimp which will fly at $6000-8000 \mathrm{ft}$ altitude, two ground-based CODARs that measure large-scale surface currents, various wind profilers, and others.

Lawrence Livermore National Laboratory's Imaging and Detection Program will take advantage of this unique site and opportunity to collect imagery with our radar that will be well ground-truthed with subsurface, surface, and above-water environmental data and possibly be compared to radar image data collected simultaneously or nearly simultaneously with another radar. Specifically, we are planning to conduct a short data collection with our Airborne Experimental Test Bed (AETB) jet aircraft-based X-band, HHpolarization synthetic aperture radar (SAR) as a piggyback to the planned COPE operation. This AETB/SAR system recently completed a major data collection as part of Project Overview conducted at AUTEC in July 1995.

LLNL's objective for the COPE experiment is as follows:

Collect SAR image data with the AETB XHH SAR containing natural internal wave-induced features over a range of grazing angles and look directions re: internal wave, sea, and wind directions, and characterize the internal wave-induced modulations and ambient clutter statistics as a function of these radar parameters and environmental conditions (which will vary naturally over the data collection period).

We plan to accomplish this in a three-day data collection on 14,15 , and 16 September 1995. Should there be problems with bad weather or mechanical problems with the AETB/SAR, we could stay up to 19 September (up to three additional days). The operations we plan are described in the next section. Also included in this short write-up is a list of supporting data we will ask ETL to collect (we would formally request the data after the completion of the experiment). 


\section{Planned LLNL Operations in COPE}

We plan to fly three identical missions as illustrated in the attached figure, on three consecutive days. We desire to image different surface effects associated with internal waves under different subsurface, surface, and above-water conditions. We will plan for all flights to be conducted during daylight hours, with approximate on-station times as follows:

\begin{tabular}{|c|c|c|}
\hline Flight 1. & September & $1500-1800$ (local) \\
\hline Flight 2 & September & $1200-1500$ \\
\hline Flight 3 & September & $0900-1200$ \\
\hline
\end{tabular}

The reason for flying at different times of day is that if there is any diurnal pattern to environmental conditions (e.g., calmer winds in the morning, picking up in the afternoon), our data collection will cover that range of conditions.

In each flight, we plan on flying at three different altitudes to provide three different grazing angles. As shown in the attached figure, at each of the three altitudes we plan to fly eight (8) straight and level passes, each about $20 \mathrm{~km}$ in length. Six of the passes will be centered on the FLIP instrumentation platform moored offshore. These six passes will be in an asterisk pattern; the six passes will have their headings 60 degrees apart. We will likely fly headings of north, $60^{\circ}, 120^{\circ}, \ldots 300^{\circ}$ in the order that is most efficiently flown by the aircraft. The remaining two passes will be parallel to the coast where long-crested internal waves whose wavefronts are roughly parallel to the coast have been observed visually. The three grazing angles we desire are $5^{\circ}$, $20^{\circ}$, and $45^{\circ}$. The design altitudes for these are $500 \mathrm{ft}, 5600 \mathrm{ft}$, and $23,000 \mathrm{ft}$ which were the altitudes flown in Project Overview at AUTEC. We may adjust the altitudes for the COPE flights depending on the strength of the radar backscatter on a given day. We will denote the images as Flight Number (1, 2, or 3$), 5^{\circ}, 20^{\circ}$, or $45^{\circ}$ grazing angle, and Pass number (1 to 8 ).

The aircraft will leave Van Nuys Airport on the morning of 14 September. It will refuel somewhere en route to the COPE site (NAS Alameda, Travis AFB are candidate sites), and perform the first day's data collection. It will land at Naval Air Station Whidbey Island, Washington which will be its base for the remainder of the experiment. After the third day's data collection, the aircraft will transit back to Van Nuys, again with a stop for fuel in between.

The aircraft will communicate with the ground via radio frequency 122.925 MHz. The aircraft's call sign will be "Hughes 75" (tail number is $575 \mathrm{HA}$ ). The LLNL experiment leader on the ground (at the ETL lidar van) will use the call sign "Lima Base". 


\section{Data Requirements}

A major factor in our desire to perform a data collection during COPE is the environmental data collection systems and another radar, all of which will be in place. We anticipate requesting the following data to support interpretation of our imagery:

CTD profiles

ADCP current profiles

Wind speed and direction

Wave height

Air and sea surface temperature

\author{
Several (one hour apart) during \\ overflight each day \\ Continuously recorded during \\ overflight each day \\ Continuously recorded during \\ overflight each day \\ Continuously recorded during \\ overflight each day \\ Continuously recorded during \\ overflight each day
}

In addition to the environmental data, it would be of much value to compare our radar imagery ETL's land based data. We desire that ETL collect radar data with their system during our data collection. Should there be interference between the LLNL X-band SAR and the ETL land-based radar, we would request the ETL radar be turned off but be turned on and dasta be recorded when the aircraft leaves the area. Data from two systems coincident in time is obviously the best for intercomparisons, but if that is impossible, data adjacent in time with continuous environmental data would have some value.

\section{Contingency Days}

Should the aircraft be grounded due to weather or mechanical problems with the AETB/SAR system, we desire to stay up to another three days (19 September at the latest) to achieve our three day's data collections. Note that any weather situation that would cause a delay would have to be severe -- a severe storm or extremely high ( $>30$ knot) winds. Note that the aircraft is all-weather and can fly IFR over or through clouds. Clouds do not affect the operation of our radar. 


\section{Coastal Ocean Probing Experiment (COPE) Proposed AETB Flight Profiles}

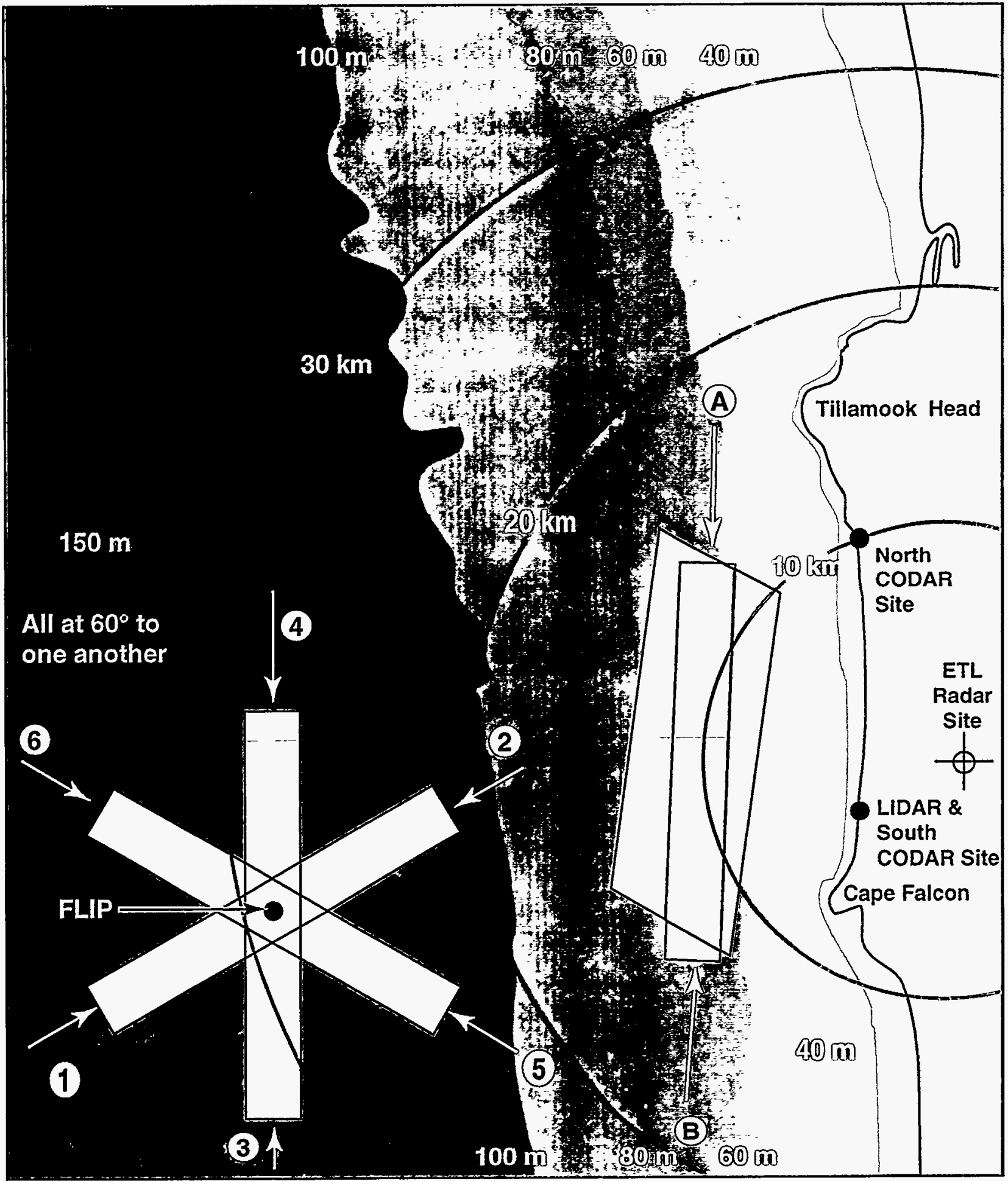

\section{SAR Imaging Swath}

1-6-From different directions over FLIP

A \& B: Coastline imaging

\begin{tabular}{|c|c|c|c|}
\hline $\begin{array}{c}\text { Grazing } \\
\text { Angle }\end{array}$ & $\begin{array}{c}\text { AVC } \\
\text { Alt. }\end{array}$ & $\begin{array}{c}\text { Coastline } \\
\text { Imaging A \& B }\end{array}$ & $\begin{array}{c}\text { Flip } \\
1-6\end{array}$ \\
\hline $5^{\circ}$ & $500^{\prime}$ & 2 passes & 6 passes \\
\hline $20^{\circ}$ & $5600^{\prime}$ & 2 & 6 \\
\hline $45^{\circ}$ & $23,000^{\prime}$ & 2 & 6 \\
\hline \multicolumn{3}{|c|}{ Note: Each pass is approximately 10 miles $(16 \mathrm{~km})$} \\
and 3 min. of data collection \\
\hline
\end{tabular}

